\title{
KINETICS OF BENZYLPENICILLIN METABOLISM IN ISOLATED RAT HEPATOCYTES
}

\author{
IKumI TAMAI and AKIRA TsuJI* \\ Faculty of Pharmaceutical Sciences, Kanazawa University, \\ Takara-machi, Kanazawa 920, Japan
}

(Received for publication September 29, 1986)

\begin{abstract}
The metabolism of benzylpenicillin (PCG) in isolated rat hepatocytes was investigated. The evidence of metabolizing activity for PCG in hepatic cells was obtained as follows; the disappearance rate of PCG from the incubation medium followed Michaelis-Menten kinetics and was dependent on the cellular protein concentration, while PCG did not disappear when it was incubated with cells denaturated by heat. The rate of disappearance of PCG was reduced significantly in the presence of the structural analogue of PCG such as phenoxymethylpenicillin in the incubation medium. The major metabolite of PCG was identified, by high performance liquid chromatographic analysis, to be penicilloic acid (PA) of PCG. A kinetic model describing the intra- and extra-cellular concentrations of PCG and PA was developed. The proposed model fitted well the time course of changes in the concentration of PCG and PA. The clearance of the uptake of PCG by isolated hepatocytes was evaluated to be about 23-times greater than that of metabolism of PCG.
\end{abstract}

To clarify the mechanism of the biliary excretion of $\beta$-lactam antibiotics, the mechanism of uptake of the antibiotics by isolated rat hepatocytes has been studied in our laboratory. ${ }^{1 \sim 3)}$ The uptake system is composed of saturable carrier-mediated and non-saturable passive diffusion processes. ${ }^{1)}$ Although the amino- $\beta$-lactam antibiotics such as ciclacillin, cephalexin and cephradine are transported via a peptide carrier in the brush-border membrane of the intestine ${ }^{4 \sim 6)}$ and kidney, ${ }^{7,8)}$ all types of $\beta$-lactam antibiotics transport through a common carrier system in the liver, which shares the same affinity site with organic anions. ${ }^{2,3)}$ However, we failed to find factors for determining the biliary excretion.

$\beta$-Lactam antibiotics taken up by hepatic cells are presumed to undergo the following fate; intracellular binding, metabolism and release through the sinusoidal and/or bile canalicular membrane. With respect to the intracellular binding of $\beta$-lactam antibiotics, the important role of the organic anionbinding protein, ligandin, has been well documented.9,10) In contrast, the metabolic fate of $\beta$-lactam antibiotics in the liver is still unclear. Several investigators have analyzed the metabolites of $\beta$-lactam antibiotics in urine after oral or intravenous administration to animals ${ }^{11-13)}$ or man..$^{14,15)}$ Since not only the $\beta$-lactam ring but the moiety of the side chains at the 6-position of penicillins and at the 3and/or 7-position of cephalosporins are easily bio-degraded in several tissues (small intestine, gut content and kidney) as well as the liver, these investigators ${ }^{11}{ }^{15)}$ did not necessarily focus on the metabolism in the liver. KIND et al. ${ }^{16)}$ and Coullnard et al. ${ }^{17)}$ demonstrated the loss of antimicrobial activity of $\beta$-lactam antibiotics, respectively in isolated perfused liver and liver homogenate. However, the detailed fate and the mechanism of inactivation of these antibiotics have not been elucidated as yet.

Isolated hepatocytes provide a useful tool for studying not only hepatic transport but also the metabolic aspects, as they maintain the membrane integrity and satisfy their cofactors needed for metabolism. Because of this benefit, many studies of hepatic transport and metabolism of drugs 
have been done with this system. ${ }^{18 \sim 21)}$

The purposes of the present study are to find evidence for the existence of metabolism of $\beta$-lactam antibiotics in the liver and to analyze the kinetics of the transport and metabolic aspects of the antibiotics, especially benzylpenicillin, in isolated hepatocytes.

\section{Materials and Methods}

Materials

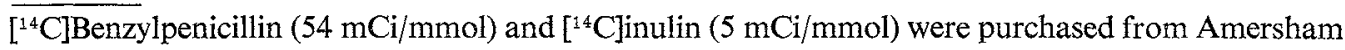
International Ltd., Amersham, U.K. Collagenase (Clostridiopeptidase A) was purchased from Boehringer-Mannheim $\mathrm{GmbH}$, Mannheim, FRG. Bovine serum albumin (BSA), fraction-V was purchased from Sigma Chemical, Co., St. Louis, MO, U.S.A., and silicon oil $(\mathrm{d}=1.05)$ from Aldrich Chemical Co., Milwaukee, WI, U.S.A.

The $\beta$-lactam antibiotics used in this work were kindly supplied as follows; ampicillin (ABPC) from Takeda Chemical Industries, Ltd., Osaka, Japan; benzylpenicillin (PCG) and phenoxymethylpenicillin (PCV) from Meiji Seika Kaisha, Ltd., Tokyo, Japan; cefpiramide (CPM) from Sumitomo Chemical and Industrial Co., Osaka, Japan, and Yamanouchi Pharmaceutical Co., Ltd., Tokyo, Japan. All other reagents were of reagent grade and were used without further purification.

\section{Preparation of Isolated Rat Hepatocytes}

Isolated hepatocytes from male Wistar rats weighing $270 \sim 320 \mathrm{~g}$ (Sankyo Labolatories Co., Toyama, Japan) were prepared according to the procedure of Moldeus et al. ${ }^{22}$ The washed cells were dispersed in incubation medium containing bovine serum albumin $2 \%, \mathrm{NaCl} 118 \mathrm{~mm}, \mathrm{KCl} 5.0 \mathrm{~mm}$, $\mathrm{MgSO}_{4} 1.2 \mathrm{~mm}$, glucose $10 \mathrm{~mm}$ and $\mathrm{CaCl}_{2} 2.5 \mathrm{~mm}$, buffered with $\mathrm{KH}_{2} \mathrm{PO}_{4} 1.2 \mathrm{~mm}, \mathrm{NaHCO}_{3} 25 \mathrm{~mm}$ and 4-(2-hydroxyethyl)-1-piperazine ethanesulfonic acid $13 \mathrm{~mm}$ to $\mathrm{pH} 7.4$, equilibrated with $95 \%$ $\mathrm{O}_{2} / 5 \% \mathrm{CO}_{2}$ and kept at $4{ }^{\circ} \mathrm{C}$ until use. The viability of each cell preparation was routinely checked both by the lactate dehydrogenase latency test and the trypan blue staining. The detailed procedures of cell isolation and the viability test were described previously. ${ }^{17}$

\section{Metabolism Studies}

One-milliliter quantities of hepatocyte suspension containing approximately $30 \mathrm{mg}$ of cellular protein were incubated with shaking $(130 \mathrm{cycles} /$ minute $)$ at $37^{\circ} \mathrm{C}$ for 5 minutes. The metabolic reaction was initiated by the addition of $1 \mathrm{ml}$ of PCG solution dissolved in incubation medium without BSA into the preincubated cell suspension to produce the desired concentration of PCG. For the study of inhibitory effect, each inhibitor was added at the initiation of the metabolic reaction.

To terminate the metabolic reaction, the following two methods were used. In the first method, samples $(0.2 \mathrm{ml})$ of the cell suspension were taken at $0,5,15,30,45$ and 60 minutes, transferred to $1.5-\mathrm{ml}$ plastic microcentrifuge tubes containing $0.2 \mathrm{ml}$ of acetonitrile to stop the metabolic reaction, mixed well and finally placed in an ice-cold bath. These samples were centrifuged at $15,000 \times g$ in an Eppendorf microcentrifuge (Type 5412, Eppendorf Co.) for 15 seconds, and the resultant supernatants were kept frozen until they were analyzed. The treatment of the cells with acetonitrile did not produce any significant precipitation of PCG from the reaction medium.

In the second method, since it is difficult to detect the amounts of intracellular PCG and degradative products of PCG by monitoring the UV absorbance, $\left[{ }^{14} \mathrm{C}\right] \mathrm{PCG}$ was used to determine separately the intra- and extra-cellular concentrations of PCG and its metabolic products. Samples $(0.2 \mathrm{ml})$ of the cell suspension containing $\left.{ }^{14} \mathrm{C}\right] \mathrm{PCG}$ and its metabolites were taken at $1,2,5,10,20,30$ and 60 minutes and transferred to $0.4-\mathrm{ml}$ plastic microcentrifuge tubes containing $100 \mu \mathrm{l}$ of silicon oil and $50 \mu 1$ of $3 \mathrm{M} \mathrm{KCl}$. Immediately after centrifugation at $15,000 \times g$ for 15 seconds, the mixture was frozen by placing the tube in a dry-ice/ethanol bath. The resultant supernatant on the silicon oil was used to determine the extracellular concentration of PCG and its metabolite and deproteinized by mixing it with acetonitrile at a volume ratio of $1: 1$ and centrifuged at $15,000 \times g$. The cells precipitated in $3 \mathrm{M} \mathrm{KCl}$ solutions were immersed in $0.3 \mathrm{ml}$ of distilled water in a $1.5-\mathrm{ml}$ plastic microcentrifuge tube, 
and sonicated to release the intracellular substrates. An aliquot of $0.2 \mathrm{ml}$ of the sonicated cell suspension was transferred to a $0.5-\mathrm{ml}$ plastic microcentrifuge tube containing $0.2 \mathrm{ml}$ of acetonitrile, mixed well to precipitate protein and centrifuged at $15,000 \times g$. The resultant supernatant was used to determine the intracellular substrate concentration.

The extracellular water content of the hepatocytes was corrected from the values determined by incubating the cells with $\left.{ }^{[14} \mathrm{C}\right]$ inulin in each experiment. The intracellular volume used for calculation was $2.5 \mu 1 / \mathrm{mg}$ of protein. ${ }^{23)}$ All studies were performed within 4 hours after cell isolation. Cellular protein was measured by the method of LowRY et al. ${ }^{243}$ with BSA used as a standard.

\section{Analytical Procedure}

The prepared samples were filtered through a membrane filter (Type HV, $0.45 \mu \mathrm{m}$, Nihon Millipore Ltd., Tokyo, Japan). The PCG concentration in the sample obtained by the first method was determined by high performance liquid chromatographic (HPLC) assay. The HPLC system was equipped with a constant flow pump BIP-I, variable-wavelength UV detector UVIDEC 100-III (Japan Spectroscopic Co., Tokyo), and a Chromatopac C-R3A recorder-integrator (Shimadzu Co., Kyoto, Japan). The analytical column used was a reversed phase column, $\mu$ Bondapak $C_{18}(30 \mathrm{~cm} \times 3.9 \mathrm{~mm}$, Waters Associate Inc., Milford, MA, U.S.A.) packed in this laboratory. A pre-column, $\mathrm{C}_{18} /$ Corasil $(3 \mathrm{~cm} \times 4 \mathrm{~mm}$, Waters Associate) was used to guard the analytical column. The mobile phase was a mixture of acetonitrile - acetic acid - water $(35: 0.05: 65)$ containing $0.01 \mathrm{M}$ tetra- $N$-butylammonium bromide and $0.01 \mathrm{~m}$ ammonium acetate. The flow rate of the mobile phase was $1.5 \mathrm{ml} / \mathrm{minute}$ and the eluent was monitored at $230 \mathrm{~nm}$.

In the experiment carried out by the second method, both extra- and intra-cellular substrate concentrations were determined from the radioactivity of the fractions separated by HPLC. The prepared samples were applied to the HPLC system under the same conditions as in the first method except for the use of a constant flow pump LC-5A (Shimadzu, Co.). Fractions $(0.4 \sim 0.8 \mathrm{ml}$ ) of the eluent were collected directly into scintillation vials containing $10 \mathrm{ml}$ of scintillation fluid (ACS II, Amersham). Radioactivity of each fraction was determined by an Aloka LSC-671 liquid scintillation counter (Aloka, Japan).

\section{Data Analysis}

The data were analyzed with a FACOM M-360 AP digital computer (Information Processing Center, Kanazawa University, Kanazawa, Japan). The kinetic parameters for the metabolism and simulation studies were estimated by a nonlinear least-squares regression analysis program, NONLIN.25)

\section{Results}

PCG at an initial concentration of $0.1 \mathrm{~mm}$ was incubated with isolated rat hepatocytes varying the amounts of cellular protein. The disappearance of PCG from the incubation medium was depending in a linear manner with respect to the cellular protein concentration. When PCG was incubated with cells denaturated by heat $\left(100^{\circ} \mathrm{C}, 5\right.$ minutes), PCG did not disappear from the reaction medium.

The relationship between the concentration of PCG and the rate of its disappearance from the reaction medium is shown in Fig. 1 as a Lineweaver-Burk plot. The rate of disappearance of PCG was estimated from the linear regression analysis of the amount disappeared at 5, 15, 30, 45 and 60 minutes and was expressed as the amount of PCG (nmol) disappeared per minute per mg protein. The result indicates that the rate of disappearance of PCG is saturable and appears to follow MichaelisMenten kinetics. From the nonliniear least-squares regression analysis, the maximum rate of disappearance of PCG (Vmax) was estimated to be $0.68 \pm 0.03 \mathrm{nmol} /$ minute/mg of protein (mean $\pm \mathrm{SD}$ ) and the Michaelis constant $(\mathrm{Km})$ by using the initial extracellular concentration to be $953 \pm 83 \mu \mathrm{M}$.

Table 1 shows the rate of disappearance of $0.1 \mathrm{mM}$ PCG from the reaction medium in the absence and the presence of CPM, ABPC or PCV as inhibitors at the concentration of $2 \mathrm{~mm}$. The results are 
Fig. 1. Concentration dependence of the rate of disappearance of PCG from the reaction medium.

Each point represents the mean of three to six experiments.

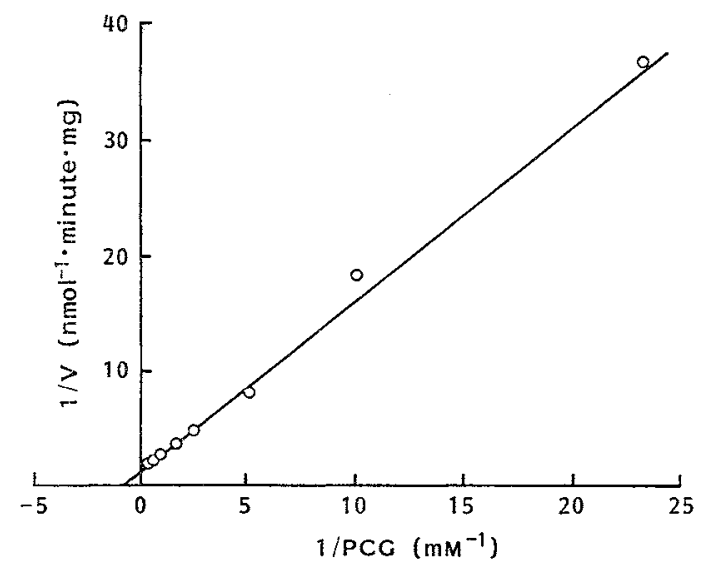

Fig. 2.

(a) High performance liquid chromatogram of intracellular ${ }^{14} \mathrm{C}$ monitored by scintillation counter after incubation of hepatocytes with $\left[{ }^{14} \mathrm{C}\right] \mathrm{PCG}$ for 30 minutes.

(b) High performance liquid chromatogram of standard drugs of PCG and its penicilloic acid monitored at $230 \mathrm{~nm}$.

(a)

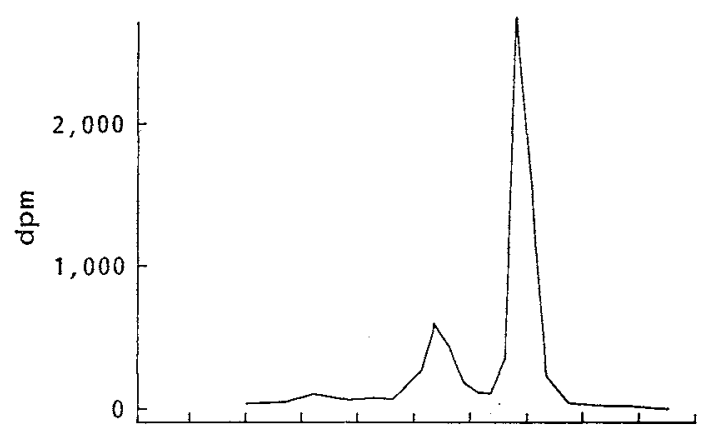

(b)

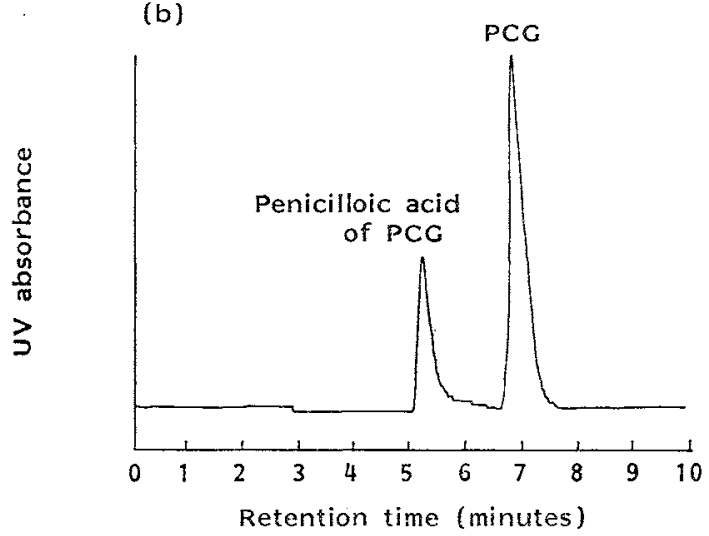

expressed as the percentage of the rate of disappearance in a control study. CPM, ABPC and $\mathrm{PCV}$ reduced the control rate to $53.4 \pm 3.0$ (mean \pm S.E.M.), $60.7 \pm 3.8$ and $11.2 \pm 2.9$ percentage of control. These three $\beta$-lactam antibiotics also reduced the uptake of PCG by hepatocytes to $53.0 \pm 1.6,52.8 \pm 2.9$ and $22.2 \pm 1.9$ percentage of control. If competition between PCG and inhibitor occurs at the metabolic step, the extent of inhibition in the metabolism should be larger than that in the uptake by hepatocytes. In the case of ABPC and CPM, the extent of inhibition of disappearance of PCG was not significantly different from that in the uptake of

Table 1. Effect ${ }^{2}$ of $\beta$-lactam antibiotics on the uptake and metabolism of benzylpenicillin in isolated hepatocytes.

\begin{tabular}{|c|c|c|}
\hline & $\begin{array}{l}\text { Uptake of } \\
\text { benzyl- } \\
\text { penicillin }\end{array}$ & $\begin{array}{l}\text { Metabolism of } \\
\text { benzyl- } \\
\text { penicillin }\end{array}$ \\
\hline \multirow{4}{*}{$\begin{array}{l}\text { Control } \\
\text { + Cefpiramide } \\
\text { +Ampicillin } \\
\text { + Phenoxymethyl- } \\
\text { penicillin }\end{array}$} & 100 & 100 \\
\hline & $53.0 \pm 1.6$ & $53.4 \pm 3.0$ \\
\hline & $52.8 \pm 2.9$ & $60.7 \pm 3.8$ \\
\hline & $22.2 \pm 1.9$ & $11.2 \pm 2.9^{*}$ \\
\hline \multicolumn{3}{|c|}{$\begin{array}{l}\text { Each value is expressed as mean } \pm \text { S.E.M. in } \\
\text { percentage of the control uptake or metabolism. } \\
\text { The concentrations of benzylpenicillin and in- } \\
\text { hibitors were } 0.1 \text { and } 2.0 \mathrm{~mm} \text {, respectively. } \\
\text { The value indicated by } * \text { is significant when } \\
\text { compared with each inhibitor group }(P<0.05) \text {. } \\
\text { The number of experiments performed was } \\
\text { three to seven. }\end{array}$} \\
\hline
\end{tabular}

Fig. 3. Schematic representation of cellular transport and metabolism of PCG in hepatocytes.

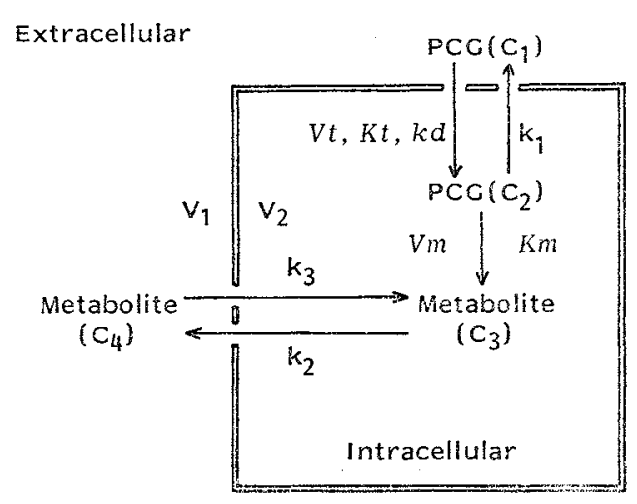


PCG by hepatocytes. On the other hand, PCV inhibited the disappearance of PCG much more than the uptake of PCG by hepatocytes, the difference being significant $(P<0.05)$.

Fig. $2 \mathrm{a}$ shows the fractionated high performance liquid chromatogram of ${ }^{14} \mathrm{C}$-radio-labeled compounds after reaction of $\left[{ }^{14} \mathrm{C}\right] \mathrm{PCG}$ with hepatocytes for 30 minutes. Fig. $2 b$ shows the chromatogram which was monitored with UV absorbance at $230 \mathrm{~nm}$ for authentic samples of PCG and its penicilloic acid (PA) prepared by the procedure of SCHWARTZ and DeLduce. ${ }^{28)}$ The two major peaks detected in Fig. 2a correspond to the peaks of PCG and its PA in Fig. 2b, judging from their retention times. The chromatographic analysis, therefore, indicates that the disappearance of PCG from the incubation medium was caused by the degradation of PCG to its PA.

A hypothetical model for the disposition of PCG in the isolated hepatocyte system is illustrated in Fig. 3. The disposition is assumed to undergo the following multiple steps. PCG, which is added to the reaction medium at the initiation of the metabolic reaction, is taken up by hepatocytes in a saturable rate process $(K t$ and $V t)$ and a non-saturable first-order rate process $(k d) .{ }^{\perp}$ Since the metabolite of PCG could not be detected in intracellular medium at the early stage of the reaction, metabolism is assumed to occur only in intracellular space. Consequently, a part of the intracellular PCG is degraded into PA of PCG and the rest flows out of the cells. The PA formed in the cells crosses the cell membrane and diffuse to the surrounding medium and back again into intracellular space. The step of degradation of PCG to PA follows Michaelis-Menten kinetics ( $\mathrm{Km}$ and $\mathrm{Vm}$ ) as verified in this study. The back-fluxes of PCG and the formed PA into the surrounding extracellular medium and the influx of PA into hepatocytes follow apparently the first-order rate processes $\left(k_{1}, k_{2}, k_{3}\right)$.

From these assumptions, the following mass-balance differential equations can be described.

$$
\begin{aligned}
& \mathrm{V}_{1} \mathrm{dC}_{1} / \mathrm{dt}=-V t \mathrm{C}_{1} \mathrm{P} /\left(K t+\mathrm{C}_{1}\right)-k d \mathrm{C}_{1} \mathrm{P}+\mathrm{k}_{1} \mathrm{C}_{2} \mathrm{~V}_{2} \\
& \mathrm{~V}_{2} \mathrm{dC}_{2} / \mathrm{dt}=V t \mathrm{C}_{1} \mathrm{P} /\left(K t+\mathrm{C}_{1}\right)+k d \mathrm{C}_{1} \mathrm{P}-V m \mathrm{C}_{2} \mathrm{P} /\left(K m+\mathrm{C}_{2}\right)-\mathrm{k}_{1} \mathrm{C}_{2} \mathrm{~V}_{2} \\
& \mathrm{~V}_{2} \mathrm{dC}_{3} / \mathrm{dt}=V m \mathrm{C}_{2} \mathrm{P} /\left(K m+\mathrm{C}_{2}\right)-\mathrm{k}_{2} \mathrm{C}_{3} \mathrm{~V}_{2}+\mathrm{k}_{3} \mathrm{C}_{4} \mathrm{~V}_{1} \\
& \mathrm{~V}_{1} \mathrm{dC}_{4} / \mathrm{dt}=\mathrm{k}_{2} \mathrm{C}_{3} \mathrm{~V}_{2}-\mathrm{k}_{3} \mathrm{C}_{4} \mathrm{~V}_{1}
\end{aligned}
$$

Fig. 4. Time courses of changes in extracellular (a) and intracellular (b) concentrations of PCG $(O)$ and its metabolite $(\Delta)$ after exposure of hepatocytes to $0.2 \mathrm{mM}\left[{ }^{14} \mathrm{C}\right] \mathrm{PCG}$.

Each point represents the mean \pm S.E.M. of three experiments or mean of two experiments. The intracellular volume used for calculation was $2.5 \mu 1 / \mathrm{mg}$ of protein. Solid lines are the concentrations predicted from the proposed model using the estimated parameters listed in Table 2.

(a)

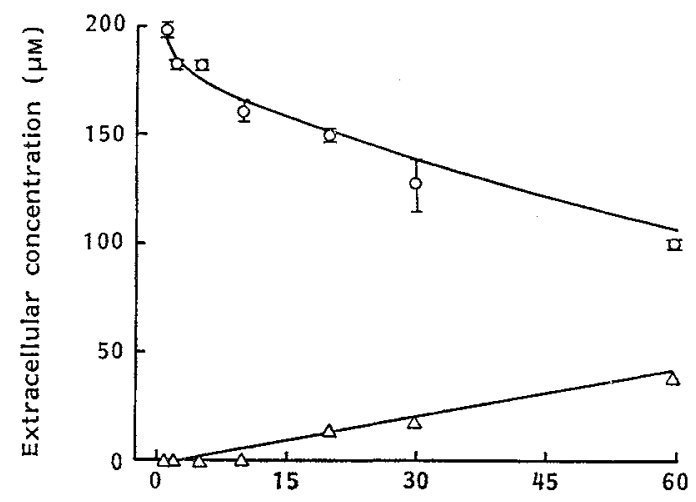

(b)

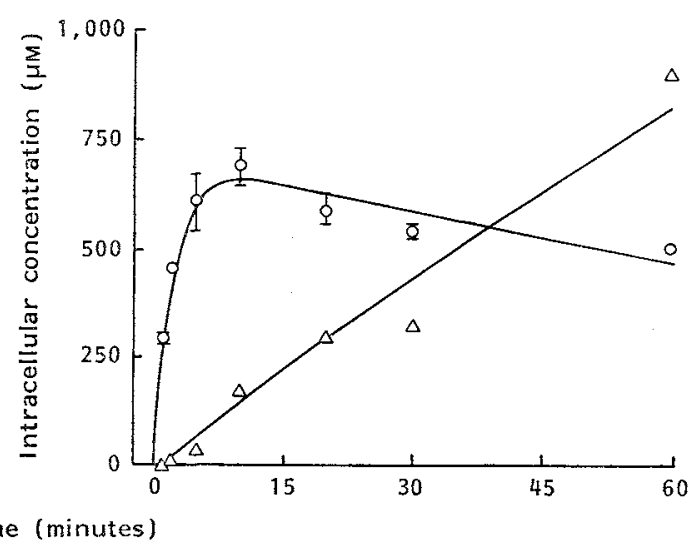


Table 2. Kinetic parameters used for prediction. ${ }^{\mathrm{a}}$

\begin{tabular}{|c|c|c|}
\hline$K t^{\mathrm{b}}$ & $473 \pm 158$ & $\mu \mathrm{M}$ \\
\hline$V t^{\mathrm{b}}$ & $2.02 \pm 0.48$ & $\mathrm{nmol} / \mathrm{minute} / \mathrm{mg}$ of protein \\
\hline$k d^{\mathrm{b}}$ & $0.58 \pm 0.012$ & $\mathrm{nmol} / \mathrm{minute} / \mathrm{mg}$ of protein $/ \mathrm{mM}$ \\
\hline$K m^{\mathrm{e}}$ & $3.60 \pm 0.314$ & $\mathrm{~mm}$ \\
\hline$V m^{d}$ & $0.68 \pm 0.03$ & $\mathrm{nmol} / \mathrm{minute} / \mathrm{mg}$ of protein \\
\hline $\mathrm{k}_{1}^{\mathrm{e}}$ & $0.31 \pm 0.01$ & /minute \\
\hline $\mathrm{k}_{2}{ }^{\theta}$ & $0.96 \pm 0.79$ & /minute \\
\hline $\mathrm{k}_{3}{ }^{\mathrm{e}}$ & $0.56 \pm 0.50$ & /minute \\
\hline$P^{f}$ & $2.55 \pm 0.24$ & /minute \\
\hline$V_{1} g$ & $194 \pm 18.0$ & $\mu 1$ \\
\hline$V_{2}{ }^{h}$ & $6.37 \pm 0.59$ & $\mu \mathrm{l}$ \\
\hline
\end{tabular}

a Each value represents the mean $\pm S D$.

b The value reported previously: See ref 1 .

c The value estimated by the least-squares nonlinear regression analysis of the data in Fig. 1, multiplied by the mean concentration ratio of intracellular/extracellular concentrations at steady-state and corrected extracellular unbound fraction (see in the text).

d The value estimated by the least-squares nonlinear regression analysis of the data in Fig. 1.

- The value estimated by the least-squares nonlinear regression analysis of the experimental concentrations of $\mathrm{C}_{1}, \mathrm{C}_{2}, \mathrm{C}_{3}$ and $\mathrm{C}_{4}$.

f The value was determined experimentally.

g The value was obtained by $200 \mu 1-\mathrm{V}_{2}$.

b The value was based on $2.5 \mu 1 / \mathrm{mg}$ of protein.

where $\mathrm{C}_{1}, \mathrm{C}_{4}, \mathrm{C}_{2}$ and $\mathrm{C}_{3}$ are the concentrations of extracellular PCG and PA and intracellular PCG and $P A$, respectively. $P$ is the amount of cellular protein in the reaction medium. $V_{1}$ and $V_{2}$ are the volume of extra- and intra-cellular compartments, respectively.

Figs. $4 \mathrm{a}$ and $\mathrm{b}$ show the observed and predicted time courses of changes in intra- and extra-cellular concentrations of PCG and PA, respectively. Table 2 shows the parameters used for the prediction. The values of $K t, V t$ and $k d$ were those reported previously from this laboratory. ${ }^{1)}$ The $K m(3.60 \pm$ $0.314 \mathrm{~mm}$ ) used was estimated by using the value obtained from Fig. 1 and the value of 4.2 , which is the mean concentration ratio of intracellular $(C) /$ extracellular(M) concentrations at steady-state measured at 5,10,20,30 and 60 minutes after initiation of the reaction, and the extracellular protein (BSA) binding. The unbound fraction of $\mathrm{PCG}$ is $90 \%$ under the present experimental conditions. ${ }^{1)}$

\section{Discussion}

For the significant decrease of PCG from the reaction medium, there are several possibilities of chemical degradation, catalytic degradation by endogenous mercaptoamine such as glutathione ${ }^{27)}$ and/or metabolism by some types of enzymes in the liver. However, since at a neutral pH the rate of chemical degradation of PCG is very $l_{0}{ }^{28,29)}$ and the concentration of glutathione is too low (about $10 \mathrm{mM}^{30)}$ ) to catalyze the PCG degradation, ${ }^{27)}$ the possibility of non-enzymatic degradation is unlikely. The facts that the increase in the rate of disappearance of PCG from the reaction medium with the increase in cellular protein concentration and the lack of disappearance of PCG in the suspension medium with cells denaturated by heat strongly indicate the participation of some kind of hepatic enzymes in PCG metabolism.

The metabolite identified from the retention time in HPLC analysis of the reaction sample was PA of PCG. PA accounted for more than $90 \%$ of the radioactivity remaining in the incubation medium except for intact PCG after 30 minutes of reaction. No apparent peak corresponding to the retention time for 6-aminopenicillanic acid, which has been suggested by $\mathrm{KIND}^{18)}$ as one of the metabolite of PCG in liver, was detected. Consequently, in this kinetic study, PA is pre- 
sumed to be the exclusive metabolite of PCG in the liver. As seen in Fig. 1, the rate of metabolism of PCG to PA was saturable and followed the Michaelis-Menten kinetics of enzyme reaction. This saturation kinetics in the rate of disappearance of PCG support the idea that the hepatic enzyme has the ability to metabolize PCG to PA in the similar manner that $\beta$-lactamase does.

In general, competition between a substrate and its structural analogue is observed in an enzymatic reaction. The inhibitory effect of PCV, ABPC and CPM on PCG metabolism (Table 1) are summarized as follows; both ABPC and CPM can inhibit the uptake of PCG by hepatocytes as reported previously ${ }^{1,3)}$ and the extents of inhibition between metabolism and uptake, were determined to be almost the same. Therefore, the apparent inhibition of metabolism by ABPC and CPM is thought to be caused by reduction in the cellular uptake of PCG. It is reasonable to consider that CPM does not compete with PCG for the metabolizing enzyme from the fact that no metabolites of this antibiotic are known to be present in rats. ${ }^{31}$ ABPC is expected to compete in the metabolic reaction with PCG, since in vivo inactivation of this antibiotic has been reported. The absence of an inhibitory effect of $\mathrm{ABPC}$ on the metabolism of PCG seems to be due to the reasons that the affinity of ABPC for the metabolizing enzyme is low in comparison with that of PCG, and/or to that ABPC has a different metabolic pathway from PCG. The inhibitory effect of PCV on PCG metabolism was significantly greater than that on PCG uptake by hepatocyte. This finding suggests that PCV competes in the step of metabolism of PCG as well as in the step of the uptake by hepatocytes, as metabolism of PCV to its PA has been reported. ${ }^{15)}$ The observed competition in the rate of degradation in the presence of substrate analogue also supports the idea that the degradation of PCG is caused by metabolism by hepatic enzymes.

From the present kinetic study showing the trans-membrane exchange and metabolism of PCG (Fig. 3), the time courses of changes in the intracellular/extracellular concentration ratios (C/M ratio) of PCG and PA can be evaluated. The value of $\left(\mathrm{k}_{3} \mathrm{~V}_{1}\right) /\left(\mathrm{k}_{2} \mathrm{~V}_{2}\right)$ is about 17 , which correspond to the $\mathrm{C} / \mathrm{M}$ ratio of PA at a steady-state and is very high, suggesting that transport of PA into the liver cells is active process. In the case of $P C G$, a constant $\mathrm{C} / \mathrm{M}$ ratio was obtained to be 4.2 after 5 minutes of the reaction and was significantly higher than 1 . Furthermore, the C/M ratio of PCG at steadystate reduced remarkably to $45.7,14.3$ and 54.2 percent of control in the presence of ABPC, PCV and CPM, respectively. These results suggest that $\mathrm{PCG}$ is actively translocated through hepatic membrane.

The clearance of the uptake $(V t / K t)$ by hepatocytes is about 23-times greater than that of metabolism $(\mathrm{Vm} / \mathrm{Km})$ of PCG. Therefore, the rate limiting step of the reaction observed in the disappearance of PCG from the hepatic cell suspension is considered to be in the step of metabolism and not in the step of uptake by hepatocytes.

In summary, we clarified the metabolizing ability of PCG in hepatic cells, and successfully developed a kinetic model which can describe the time courses of intra- and extra-cellular concentrations of PCG and PA.

\section{Acknowledgments}

The authors are grateful to Dr. T. TerASAKI for his helpful discussion. They also thank Miss H. EdANAKA for her excellent technical assistance. This work was supported by Grant-in-Aid for Scientific Research from the Ministry of Education, Science and Culture, Japan.

\section{References}

1) Tsuji, A.; T. Terasaki, K. Takanosu, I. Tamai \& E. Nakashima: Uptake of benzylpenicillin, cefpiramide and cefazolin by freshly prepared rat hepatocytes. Biochem. Pharmacol. 35: 151 158, 1986

2) Terasaki, T.; I. Tamai, K. Takanosu, E. Nakashima \& A. Tsuji: Kinetic evidence for a common transport route of benzylpenicillin and probenecid by freshly prepared hepatocytes in rats. Influence of sodium ion, organic anions, amino acids and peptides on benzylpenicillin uptake. J. Pharmacobiodyn. 9: 18 28,1986

3) TAMaI, I.; T. Terasaki \& A. TsujI: Evidence for the existence of a common transport system of $\beta$-lactam 
antibiotics in isolated rat hepatocytes. J. Antibiotics 38: 1774 1780, 1985

4) Nakashima, E.; A. TsuJi, H. Mizuo \& T. Yamana: Kinetics and mechanism of in vitro uptake of amino$\beta$-lactam antibiotics by rat small intestine and relation to the intact-peptide transport system. Biochem. Pharmacol. 33: 3345 3352, 1984

5) Nakashima, E.; A. Tsuji, S. Kagatani \& T. Yamana: Intestinal absorption mechanism of amino- $\beta$ lactam antibiotics III: Kinetics of carrier-mediated transport across the rat small intestine in situ. J. Pharmacobiodyn. 7: 452 464, 1984

6) OKano, T.; K. InUr, M. TAKano \& R. HoRI: $\mathrm{H}^{+}$gradient-dependent transport of aminocephalosporins in rat intestinal brush-border membrane vesicles. Role of dipeptide transport system. Biochem. Pharmacol. 35 : $1781 \sim 1786,1986$

7) INUi, K.; T. Okano, M. Takano, H. Sarto \& R. Hori: Carrier-mediated transport of cephalexin via the dipeptide transport system in rat renal brush-border membrane vesicles. Biochim. Biophys. Acta 769: $449 \sim 454,1984$

8) InUI, K.; M. TAKano, T. OKano \& R. HoRI: $\mathrm{H}^{+}$Gradient-dependent transport of aminocephalosporins in rat renal brush-border membrane vesicles: Role of $\mathrm{H}^{+}$/organic cation antiport system. J. Pharmacol. Exp. Ther. 233: $181 \sim 185,1985$

9) Habig, W. H.; M. J. Pabst, G. Fleischner, Z. Gatmaitan, I. M. Arias \& W. B. Jakoby: The identity of glutathione S-transferase-B with ligandin, a major binding protein of liver. Proc. Natl. Acad. Sci. U.S.A. $71: 3879 \sim 3882,1974$

10) Kornguth, M. L.; R. A. Monson \& C. M. Kunin: Binding of antibiotics to a soluble protein from rat liver. J. Infect. Dis. 129: 552 558, 1974

11) Lee, C. C.; E. B. Herr \& R. C. Anderson: Pharmacological and toxicological studies on cephalothin. Clin. Med. 70: 1123 1138, 1963

12) Sullivan, H. R. \& R. E. McMahon: Metabolism of oral cephalothin and related cephalosporins in the rat. Biochem. J. 102: 976 982, 1967

13) Ryrfeldt, A.; N. O. Bodin \& E. HANSSON: Biliary excretion of ampicillin, azidocillin and benzylpenicillin in the rat. Acta Pharmacol. Toxico1. 33: 219 228, 1973

14) Hellström, K.; A. Rosen \& A. Swahn: Absorption and decomposition of potassium- ${ }^{35}$ S-phenoxymethyl penicillin. Clin. Pharmacol. Ther. 16: 826 833, 1974

15) Uno, T.; M. Masada, K. Yamaoka \& T. Nakagawa: High performance liquid chromatographic determination and pharmacokinetic investigation of amino-penicillins and their metabolites in man. Chem. Pharm. Bull. 29: 1957 1968, 1981

16) KIND, A. C.; H. N. BeAtY, F. FENSTER \& W. M. M. KIRBY: Inactivation of penicillins by the isolated rat liver. J. Lab. Clin. Med. 71: 728 735, 1968

17) Courllard, M.; J. C. Pechere, C. Morin, G. Richer \& R. Guay: Inactivation of $\beta$-lactam compounds by rat liver homogenates. Program and Abstracts of the 23th Intersci. Conf. on Antimicrob. Agents Chemother., No. 285, p. 134, Las Vegas, Oct. 24 26, 1983

18) Pang, K.S.; P. Kong, J. A. Terrell \& R. E. Billings: Metabolism of acetaminophen and phenacetin by isolated rat hepatocytes. Drug Metab. Dispos. 13: $42 \sim 50,1985$

19) Sommandossi, J. P.; D. A. Gemirtz, R. B. Diasio, C. Aubert, J. P. Cano \& I. D. Goldman: Rapid catabolism of 5-fluorouracil in freshly isolated rat hepatocytes as analyzed by high performance liquid chromatography. J. Biol. Chem. 257: $8171 \sim 8176,1982$

20) Sundheimer, D. W. \& K. Brendel: Metabolism of harmol and transport of harmol conjugates in isolated rat hepatocytes. Drug Metab. Dispos. 11: 433 440, 1983

21) Morais, J. A. \& J. G. WaGner: A model describing the disposition of phenytoin in isolated rat hepatocytes. Biopharm. Drug Dispos. 5: 357 376, 1984

22) Moldeus, P.; J. Högberg \& S. OrRenius: Isolation and use of liver cells. Methods Enzymol. 52: 60 71,1978

23) EAton, D. L. \& C. D. KlaAsSen: Carrier-mediated transport of ouabain in isolated hepatocytes. J. Pharmacol. Exp. Ther. 205: 480 488, 1978

24) Lowry, O. H.; N. J. Rosebrough, A. L. FARr \& R. J. Randall: Protein measurement with the folin phenol reagent. J. Biol. Chem. 193: 265 275, 1951

25) Metzler, C. M.; G. L. Elfling \& A. J. MCEwen: A package of computer programs for pharmacokinetic modeling. Biometrics 30:562, 1974

26) Schwartz, M. A. \& A. J. Delduce: Kinetic analysis of penicilloic acid and penicilloamides in combination: Application to products of reaction of penicillin with tromethamine (Tris) and poly-l-lysine, J. Pharm. Sci. 58: 1137 1139, 1969 
27) Yamana, T.; A. Tsum, E. Mryamoto \& E. KiYA: The reaction of benzylpenicillin with amines containing hydroxyl groups. J. Pharm. Pharmacol. 27: 771 774, 1975

28) Yamana, T.; A. Tsuj, E. Kiya \& E. Mryamoto: Physicochemical properties of $\beta$-lactam antibacterials: Deuterium solvent isotope effect on penicillin $G$ degradation rate. J. Pharm. Sci. 66: 861 866, 1977

29) Hou, J. P. \& J. W. Poole: $\beta$-Lactam antibiotics: Their physicochemical properties and biological activities in relation to structure. J. Pharm. Sci. 60: 503 532, 1971

30) Ketterer, B.: The role of nonenzymatic reactions of glutathione in xenobiotic metabolism. Drug Metab. Rev. 13: 161 187, 1982

31) Matsui, H.; K. Yano \& T. Okuda: Pharmacokinetics of the cephalosporin SM-1652 in mice, rats, rabbits, dogs, and rhesus monkeys. Antimicrob. Agents Chemother. 22: 213 217, 1982 